\title{
Uzaktan turist rehberliği eğitimi alanların memnuniyet algılarının değerlendirilmesi: Kapadokya Üniversitesi örneği *
}

\section{Evaluation of the perception for satisfaction of tourist guidance students in distance education program: the case of Cappadocia University}

Gönderim Tarihi / Received: 08.11.2021

Kabul Tarihi / Accepted: 26.12.2021

doi https://doi.org/10.31795/baunsobed.1020775

\section{Mehmet BAHAR ${ }^{* * 1}$}

Duran CANKÜL ${ }^{2}$

ÖZ: Uzaktan eğitim yıllardır eğitim alanında kullanılmaktadır. Yaşanan Covid-19 sürecinde ise eğitim hayatının bir parçası olarak uzaktan eğitim gündeme gelmiştir. Uzaktan eğitimde karşılaşılan zorluklar ve güçlüklere rağmen pandemi sona erse bile etkilerinin uzun süre devam edeceği düşünülmektedir. Dolayısıyla uzaktan eğitimde öğrencilerin motivasyonu, derslere aktif katılımları ve başarılı olmaları için öğrenci memnuniyetinin sağlanması önem arz etmektedir. Bu doğrultuda araştırmanın amacı uzaktan turist rehberliği eğitimi alanların memnuniyet algılarını belirlemektir. Araştırmada veriler anket yolu ile toplanmıştır. Araştırmada kullanılan anket Nisan-Mayıs 2021 tarihinde Kapadokya Üniversitesinden uzak eğitim ile eğitim alıp mezun olan veya halen öğrenci olan ön lisans ve yüksek lisans öğrencilerine uygulanmıştır. Ulaşılabilen anket sayısı $148^{\prime}$ dir. Elde edilen veriler frekans, aritmetik ortalama, yüzde ve standart sapma değerleri hesaplanarak betimlenmiş ve değişkenler arasında farklılık olup olmadığının test etmek için anova ve bağımsız örneklem t-testi, değişkenler arasındaki ilişkiyi belirlemek amacıyla da korelasyon analizi uygulanmıştır. Analiz sonuçlarına göre katılımcıların en yüksek algıya sahip oldukları boyut kişisel uygunluk boyutuyken, en az algıya sahip oldukları boyut teknoloji boyutudur. Ayrıca eğitim durumuna göre etkililik, program değerlendirmesi, teknoloji, materyal, değerlendirme ve destek hizmetleri boyutlarında alg1 farkı olduğu belirlenmiştir.

Anahtar Kelimeler: Uzaktan eğitim, Turist rehberliği eğitimi, Öğrenci memnuniyeti, Turizm

ABSTRACT: Distance education has been used in the field of education for years. However, In the Covid-19 period, distance education has come to the fore as a part of education life. Despite the difficulties and obstacles encountered in distance education, it is thought that even if the pandemic ends, its effects will continue for a long time. Thus, it is important to ensure student satisfaction in distance education for the motivation of students, their active participation in the courses and their success in exams. In this context, this research is aimed to determine the satisfaction perceptions of the students who receive distance tourist guidance education. For this purpose, data were obtained by using the survey technique, one of the quantitative research methods. The survey used in the research was applied to associate and graduate students who graduated or are still students at Cappadocia University with distance education in April-May 2021. The number of surveys that can be reached is 148. Arithmetic mean, frequency, percentage, and standard deviation values, and analysis of variance (anova) and independent sample t-test were used to determine whether there was a significant difference in terms of variables, and correlation analysis was applied to determine the relationship between the variables. According to the results, the dimension in which the participants have the highest perception is the personal convenience, while the dimension they have the least perception is the dimension of technology. In addition, it has been determined that there is a perception difference in the dimensions of effectiveness, program evaluation, technology, support services, material, and evaluation according to educational status.

Keywords: Distance education, Tourist guidance education, Student satisfaction, Tourism

\footnotetext{
${ }^{*}$ Bu çalışma 21. Ulusal Turizm Kongresinde bildiri olarak sunulmuştur.

${ }^{* *}$ Sorumlu Yazar / Corresponding Author

${ }^{1}$ Dr. Öğr. Üyesi, Kapadokya Üniversitesi, U.B.Y.O./ Havacılık Yönetimi, mehmet.bahar@kapadokya.edu.tr,

(D) https://orcid.org/0000-0001-5377-7292

${ }^{2}$ Doç. Dr., Eskişehir Osmangazi Üniversitesi/Turizm Fakültesi/ Gastronomi ve Mutfak Sanatları Bölümü, dcankul@ ogu.edu.tr,

(D) https://orcid.org/0000-0001-5067-6904
} 


\section{EXTENDED ABSTRACT}

\section{Literature review}

Distance education has emerged with the limitations of traditional education methods, the qualifications of the people who will participate in the education, the differences, or the increase in the number of participants. Distance education is an educational activity that is carried out by using modern communication techniques regardless of time and place of the educational materials used (Işık, Işık \& Güler, 2008). The "distance education center" was officially launched in France in 1939 for the first time. These activities, which were previously carried out by teleconferences by institutions carrying out similar training activities, are now being carried out remotely on a web-based basis in parallel with the development of computer-aided technologies (Işık \& Güler, 2008). In the 1980s, great developments and breakthroughs were experienced in this regard. As a result of these changes in this subject, many distance education institutions have been established and many people have had the opportunity of distance education. With the introduction of contemporary learning approaches, different learning desires and wishes have begun to be fulfilled (Akyürek, 2020).

A study was conducted by Yağc1, Efendi \& Akçay (2019) to determine the perspectives of tourist guidance students on the concept of distance education. In their study, in which the quotas of institutions and organizations providing tourist guidance training in Turkey were examined, Temizkan \& Ergün (2018) stated that the number of existing guides was more than the need in their study, and a planning was needed before a new tourist guiding quota was opened. In their study, Cansu \& Bahar (2021) made an analysis of the current number of tourist guides and the languages spoken by the tourists coming to our country and tried to determine the number of guides in that language per tourist coming to our country. Today, tourist guiding education is given remotely by Ayvansaray University, Cappadocia University and Muğla University as an associate degree. Distance education at the undergraduate level is not yet available.

\section{Methodology}

Quantitative research method was used to determine the satisfaction perceptions of those who received distance tourist guidance education. The survey technique was used to collect data. The survey consists of two parts. In the first part, there are statements about the demographic characteristics of the participants. The demographic information are gender, age, education level, education level and computer usage level. In the second part of the survey, there is a scale to determine the satisfaction (service quality) of those who have benefited from distance education. The scale used in the research was developed by Eygü \& Karaman (2013) and its validity and reliability were tested and proven.

\section{Findings and discussion}

$73 \%$ of the participants are male and $27 \%$ are female. Within the age range, $17.6 \%$ of the participants were "30 and under", 25.7\% "31-35", 21.6\% "36-40", 15.5\% "41-45" and 19.6\% are in the "46 and over" age group. In terms of education level, $66.9 \%$ of the participants are at associate degree and $33.1 \%$ at graduate level. While $81.8 \%$ of the participants are students, $18.2 \%$ are graduates. $52.7 \%$ of the participants use computers at advanced level, $44.6 \%$ at intermediate level and $2.7 \%$ at basic level. The mean and standard deviation values of the participants' perceptions of the statements can be summarized in terms of dimensions as follows;

- In the personal convenience dimension, the statement that the participants have highest perception is "distance education makes learning permanent", while the statement with the least perception is "it makes the student more active in terms of distance education applications".

- In the effectiveness dimension, the statement that the participants have highest perception is "I was able to interact with the lecturers of the courses when necessary", while the statement with the least perception is "I could get enough support in matters related to student affairs (registration, student certificate)".

- In the learning dimension, the statement that the participants have highest perception is "distance education is suitable for me due to the intensity of my work", while the statement with the least perception is "distance education is more effective than traditional education". 
- In terms of the evaluation of the program, the statement that the participants have highest perception is "I think this program is professionally good", while the statement with the least perception is "the program was well designed".

- In technology evaluation, the statement that the participants have highest perception is "I have a social and friendly interaction with my distance education teacher", while the statement with the least perception is "I can be like myself in my communication with my teacher in distance education and I can show what kind of a student I am really".

- In the material dimension, the statement that the participants have highest perception is "the topics in the course resources were consistent with each other", while the statement with the least perception is "the objectives that included the knowledge, skills and behaviours to be gained by the students in the course resources".

- In the evaluation dimension, the statement that the participants have highest perception is "I could easily access the course contents through the system", while the statement with the least perception is "I did not experience problems that would reduce my desire to learn".

- In the dimension of support services, the statement that the participants have highest perception is "the questions in the exam were consistent with the course contents", while the statement with the least perception is "the final exams were of a quality to evaluate my level of knowledge".

\section{Results and recommendations}

Regarding the effectiveness of distance education, it is seen that while students positively evaluate the issue of interacting with the instructors, if necessary, a similar interaction cannot be achieved in student affairs. This is thought to be because distance education students have access to student affairs, unlike formal students, only by means of e-mail, WhatsApp, and telephone. In this regard, within the framework of the total quality management approach in the university, determining a maximum period of 24 hours to 48 hours for the return of applications made via remote access and realizing this target can help correct this perception.

While the participants state that the current learning model in the learning dimension is the most suitable program for them due to their workload, they state that distance education will not replace traditional education. This reveals that distance education will never be a $100 \%$ alternative to traditional education, although it is a very important opportunity to complete the missing and needed education for those with temporal and spatial problems.

In the general evaluation of the program, the relevance of the syllabus and their content for the purpose and the consistency of the current course topics in the material dimension were found to be high, while the consistency in the knowledge, skills, and behaviour to be gained by the student because of the course was found to be low. In this respect, it is considered that the SOBE (Education Prior to Latest Knowledge) (Cappadocia University, 2021) system owned by Cappadocia University is not adequately transferred to the students. To better understand the SOBE educational philosophy and transfer it to the students, it may be beneficial to train the instructors. On the other hand, when we look at the literature, it is seen that the study carried out by Eygü \& Karaman (2013) supports the results of the research.

It is thought that the effects of the concept of "Distance Education", which has become a part of daily life due to the COVID-19 process, will continue for a long time even if the pandemic ends due to this process. Due to the necessity of this process, it is considered that those who are distant and prejudiced from distance education will have positive results because they have experienced it personally. It is suggested that such distance education programs should be made more widespread, especially in the field of social sciences, for those who could not benefit from this education for any reason, in addition to the traditional education programs that have proven their effectiveness and are indispensable in the education programs to be created from now on. 


\section{Giriş}

Uzaktan eğitim kavramı uzaktan öğrenme, ağ tabanlı öğrenme, açı öğrenme, çevrimiçi öğrenme ve esnek öğrenme gibi terimleri ve çeşitli eğitim modellerini kapsayan bir şemsiye kavramdır (Gunawardena ve McIsaac, 2004). Uzaktan eğitimi kısaca öğretenin ve öğrenenin tamamen farklı ortamlarda bulunarak, senkron veya asenkron şekilde gerçekleştirilen bir eğitim sistemi olarak tanımlanabilir (Kaçan ve Gelen, 2020). Zaman sınırlaması ve mekân kısıtlaması olmaması uzaktan eğitimi hem öğretenler hem öğrenciler için çekici bir duruma getirmeye başlamıştır (Holmberg, 1989). Günümüzde yaşanan Covid-19 pandemisi nedeniyle eğitim sektörü de diğer sektörler gibi olumsuz etkilenmiştir. Yaklaşık 1,5 milyar öğrenci ve 63 milyona yakın öğretmen pandemiden olumsuz etkilenmiştir (unesco.org, 27.03.2020) ve kısıtlamaların olduğu eğitim sektörü de çözümü uzaktan eğitim sağlayarak bulmuştur. Uzaktan eğitim örgün öğretimin bir alternatifi olarak belirtilmekte ve pandemi öncesinde de birçok ülkede kullanılmakta olduğu görülmektedir (Gökbulut, 2021).

Uzaktan eğitimde öğretimin etkililiği ve kalitesini belirleme için memnuniyet önemli bir konudur. Uzaktan eğitim ile verilen bir programın veya başlı başına bir dersin başarısı öğrenci memnuniyeti ile belirlenebilir (Merisotis ve Phipps, 1999). Uzaktan eğitimde memnuniyetsizlik ile eğitimi terk etme oranı arasında pozitif bir ilişki bulunmaktadır, çünkü bir öğrenci aldığı uzaktan eğitimden memnun kalmazsa eğitimini tamamlamama eğilimine girmektedir (McGivney, 2004). Bundan dolayı uzaktan eğitimde memnuniyetin ölçülmesi, eğitimcilere ve ilgili kurum ve kuruluşlara öğrenmenin etkinliğini ve kalitesini artırmada yardımcı olabilmektedir (Biner, Dean ve Mellinger, 1994; Schwitzer, Ancis ve Bronw, 2001).

Uzaktan eğitimin memnuniyetinin ölçülmesinin yanı sıra turist rehberliği eğitimi ile ilgili olarak verilen eğitimi de inceleyen (Eker ve Zengin, 2016); ön lisans, lisans ve lisansüstü örgün eğitim veren üniversitelerdeki turist rehberliği müfredatlarını inceleyen (Güven ve Ceylan, 2014; Topsakal, 2021); müfredatlardaki belli uzmanlık konularını inceleyen (Akdu vd., 2018; Çakmak ve İstanbullu Dinçer, 2018; Bahar 2020), müfredatları sektör beklentisi kapsamında inceleyen (Yenipınar ve Kardaş, 2019) çalışmalar mevcuttur. Yağcı, Efendi ve Akçay (2019) tarafından ise turist rehberliği öğrencilerinin uzaktan eğitim kavramına bakış açılarını belirlemek üzere bir çalışma gerçekleştirilmiştir. Türkiye'de turist rehberliği eğitimi veren kurum ve kuruluşların kontenjanlarının incelendiği çalışmada Temizkan ve Ergün (2018), mevcut rehber sayısının ihtiyaçtan fazla olduğu, yeni turist rehberliği bölümlerine yönelik kontenjanı açılmadan önce mevcutların üzerinden bir planlama gerektiğini belirtmişlerdir. Duman ve Mil ise (2008) öncelikli olarak hangi dilden kaç rehbere ihtiyaç duyulduğu ile ilgili bir tespitin gerekliliğini ifade etmişlerdir. Cansu ve Bahar (2021) yaptıkları çalışmada mevcut turist rehberi sayıları ile ülkemize gelen turistlerin konuştukları dillere göre bir analiz yaparak, ülkemize gelen turist başına düşen o dildeki rehber sayısını belirlemeye çalışmışlarıdır. Günümüzde turist rehberliği eğitimi ön lisans olarak Ayvansaray Üniversitesi, Kapadokya Üniversitesi ve Muğla Üniversitesi tarafından uzaktan eğitim şeklinde verilmektedir. Lisans düzeyinde uzaktan eğitim henüz verilmemektedir. Yüksek lisans düzeyinde ise Kapadokya Üniversitesinde tezsiz yüksek lisans programı olarak verilmektedir. Yapılan literatür taramasında turist rehberliği uzaktan eğitim alanların memnuniyeti konusuna odaklanan çalışma olmadığı belirlenmiştir. Uzaktan eğitimde memnuniyetin ölçülmesi önemli olduğundan dolayı çalışmanın amacı uzaktan turist rehberliği eğitimi alanların memnuniyet algılarını belirlemektir.

\section{Literatür taraması}

Uzaktan eğitim faaliyeti; geleneksel eğitim metotlarındaki kısıtlar, eğitime katılacak kişilerin nitelikleri, farklıkları ya da katılımcı sayısındaki artışla birlikte ortaya çıkmıştır ve kullanılan eğitim malzemelerinin zaman ve mekân gözetmeksizin modern iletişim teknikleri kullanılarak yapılan bir eğitim faaliyetidir (Işık, Işık ve Güler, 2008). Resmi olarak ilk kez 1939 yılında Fransa' da "uzaktan eğitim merkezi" faaliyete girmiştir. Önceleri benzeri eğitim faaliyetleri yürüten kurumlar telekonferans ile gerçekleştirdiği bu faaliyetler günümüzde bilgisayar destekli teknolojilerin gelişmesine paralel olarak web tabanlı olarak uzaktan bir şekilde yapılmaya başlanmıştır (Işık ve Güler, 2008). 1980'lere gelindiğinde bu konuda çok büyük gelişmeler sağlanmış ve atılımlar yaşanmıştır. Bu konuda yaşanan bu değişimlerin bir sonucu olarak da birçok sayıda uzaktan eğitim veren kurumlar oluşmuş ve bu sayede birçok kişi uzaktan öğrenim imkanına kavuşmuştur. Çağdaş öğrenim yaklaşımlarının ortaya konulmasıyla birlikte değişik öğrenme arzu ve istekleri yerine getirilmeye başlanmıştır (Akyürek, 2020). 
Uzaktan eğitim ile ilgili yapılan alan yazın taramalarında Gökmen, Duman ve Horzum (2016) gerçekleştirdikleri araştırmada uzaktan eğitimin tanımını yaparak ilgili öğrenme teorilerinin temel ilkelerini ortaya koyarak açıklamaya çalışmışlardır. Tuncer (2007), uzaktan eğitimin öğrenci sağlığ1 üzerine ne gibi etkileri olduğu konusuna dikkati çekmiştir. Gökçe (2008), yaptı̆̆ 1 çalışmada üniversitelerin küreselleşme çabalarındaki uzaktan eğitimin rolünü irdelemiştir. Metin, Karaman ve Şaştım (2017), öğrencilerin uzaktan eğitim sistemine bakış açılarını öğrenme amacıyla gerçekleştirdikleri çalışmalarında uzaktan eğitim ile verilen İngilizce derslerinin yüz yüze verilen dersler kadar verimli bulunup bulunmadığı sorusuna, katılımcıların \%67'si verimli bulmadıklarını belirterek memnuniyetsizliklerini ortaya koymuşlardır. Örgün eğitim alan öğrencilerin uzaktan eğitimden memnuniyetlerinin yanında uzaktan eğitimi gönüllü olarak tercih etmiş olanlar ile ilgili Eygü ve Karaman (2013)'ın Atatürk Üniversitesi Uzaktan Eğitim ve Araştırma öğrencileri ile gerçekleştirdikleri "öğrencilerin memnuniyet algıları" üzerine çalışmada ise uzaktan eğitim programlarını kendileri için büyük bir firsat olarak gördükleri, işlerinin yoğunluğu sebebiyle bu tür bir eğitim programını tercih ettiklerini ifade etmişlerdir. $\mathrm{Bu}$ çalışmaya ilaveten yine uzaktan eğitim alan öğrencilerin memnuniyetlerini ölçmeye yönelik (Eygü ve Kahraman, 2015; Özkılıçcı ve Cantürk, 2020; Bayram, 2020) bazı çalışmalar bulunmaktadır. Çalışma sonuçlarında uzaktan eğitim alan öğrencilerin kendilerini gruba dahil etmeleri, özel mesajlaşma, tartışma panosu, sohbet veya yüz yüze etkileşim gibi unsurlarla etkileşime girmelerinin önemli olduğunu göstermektedir. Çünkü etkileşim içinde olan öğrenciler uzaktan eğitimde daha fazla katılmaya gönüllü olmakta ve böylelikle öğrencilerin memnuniyeti ve başarıları da olumlu yönde artmaktadır (Ilgaz ve Aşkar, 2009).

Nasser ve Abouchedid (2000) uzaktan eğitime yönelik tutum ve endişelere yönelik çalışma gerçekleştirmiştir. çalışmanın sonucunda; okul müdürleri ve öğretmenlerinin uzaktan eğitim konusunda olumsuz tutuma sahip oldukları görülmüştür. Chang ve Tung (2008) tarafından yapılan araştırmada öğrencilerin web tabanlı uzaktan eğitim araçlarını kullanma eğilimleri incelenmiştir. Araştırma sonucunda öğrencilerin web tabanlı uzaktan eğitimi tercih etmelerinin bilgisayar öz- yeterlik algıları ile dersin işlendiği web sitesinin niteliğinin yüksek olması, öğrenci tercihine uygun, faydalı ve kullanıc1 dostu olmasından kaynaklandığı saptanmıştır. Sadera, Robertson, Song ve Midon (2009) uzaktan eğitim başarısında toplum etkisini amaçladıkları çalışmada adlı öğrencilerin toplum algısı ve uzaktan eğitim başarıları arasında olumlu bir etki olduğu görülmüştür. Betts (2014) öğretim üyelerinin çevrimiçi ve karma eğitime katılımını ve elde tutulmasını etkileyen faktörlerini belirlemek için gerçekleştirdiği çalışmada uzaktan eğitim katılımcı tutumlarının, çevrimiçi programlara $\% 62$ pozitif, $\% 20$ nötr ve $\% 18$ negatif; karma programlara karş1 \%84'ünün pozitif, \%11'inin nötr ve \%5'inin negatif olduğu görülmüştür. Poellhuber, Anderson ve Roy (2011) tarafından yapılan araştırmada Kanada'da uzaktan eğitim ile öğrenim gören öğrencilerin sosyal ağ araçlarını kullanma becerileri, bu araçları eğitimde kullanmaya yönelik ilgileri ve iş birliği düzeyleri incelenmiştir. Araştırma sonucu, öğrencilerin farklı görüş ve deneyimlere sahip olduğunu göstermektedir. Mokoena (2017) tarafindan yapılan araştırmada Güney Afrikalı öğretmen adaylarının açık ve uzaktan eğitim okulundaki öğretim uygulamasına ilişkin deneyimleri incelenmiştir. Çalışma sonucunda öğretmen adaylarının danışmanlık, denetim ve eğitim kurumlarına zamanında yerleştirilme konusunda sorunlar yaşadıkları ve öğretmen adayı danışmanlarının ve üniversite denetmenlerinin daha etkili çalışabilmeleri için yetkilendirilmesi gerektiği belirlenmiştir.

Adnan ve Anwar (2020) yaptıkları araştırmada, Pakistan'da yüksek öğrenim gören öğrencilerin Covid19 salgını sürecinde üniversitede derslerin zorunlu dijital ve uzaktan eğitim olarak verilmesine ilişkin bakış açıları incelenmiştir. Araştırıma sonucunda; öğrencilerin çoğunluğunun teknolojik ve maddi problemler nedeniyle internete erişememeleri, yüz yüze eğitimle karşıllaştırıldığında uzaktan eğitimde etkileşim eksikliğinin bulunması, geri bildirim ve cevap verme/alma firsatının olmaması, sınıf içi sosyalleşmenin olmaması ve Pakistan gibi gelişmemiş ülkelerde internet tabanlı uzaktan eğitimin istenilen şekilde başarılı olamayacağı sonuçlarına ulaşılmıştır. Sujarwo, Sukmawati, Akhiruddin, Ridwan ve Siradjuddin (2020) yaptıkları araştırmada, üniversite öğrencilerinin Covid-19 salgını sürecinde aldıkları çevrimiçi eğitimden yararlanmaya iliş̧in algıları incelenmiştir Araştırma sonucunda; öğrencilerin daha önce uzaktan eğitim alma deneyimlerinin olmadığı, Covid-19 salgını sürecinde her yerden ve istedikleri zaman eğitime katılma olanağını beğendikleri, eğitim için en iyi kullanılan 
uygulamanın WhatsApp olduğu, Covid-19 salgının öğrencilerin çevrimiçi eğitime bakış açılarından olumlu bir etki oluşturduğu sonuçlarına ulaşılmıştır. Afşar ve Büyükdoğan (2020) yaptıkları araştırmada, öğrencilerin Covid-19 salgını aşamasında uzaktan eğitimle alakalı öz yeterlilikleri ve uzaktan eğitim yöntemine ilişkin bakış açıları incelenmiştir. Araştırma sonucunda; öğrencilerin uzaktan eğitim yöntemini tercih ettikleri, uzaktan eğitim yöntemleri ve uygulamalarını verimli ve kolay buldukları, uzaktan eğitimin internete bağlı araştırma becerilerini arttırdığı, zamanı iyi kullanmalarını sağladığı, öğrencilerin yarısının uzaktan eğitimi ilginç ve keyifli bulduğu, uzaktan eğitim sürecinde daha çok teknik konularda problemlerle karşılaşıldığı sonuçlarına ulaşılmıştır.

\section{Yöntem}

Uzaktan turist rehberliği eğitimi alanların memnuniyet algılarını belirleme amacıyla nicel araştırma yönteminden faydalanılmıştır. Veriler anket aracılığıyla elde edilmiş̧ir. Anket iki bölüm olacak şekilde hazırlanmıştır. Birinci bölümde çalışma katılımcılarının demografik özelliklerine yönelik sorulara yer verilmiştir. Bu demografik bilgiler cinsiyet, yaş, eğitim düzeyi, eğitim durumu ve bilgisayar kullanma düzeyidir. Anketin ikinci bölümünde ise uzaktan eğitimden faydalanmış olanların memnuniyetini (hizmet kalitesini) belirlemek için ölçek yer almaktadır. Araştırmada Eygü ve Karaman (2013) tarafından uzaktan eğitimden faydalanmış olanların memnuniyetimi ölçmeye yönelik olarak geliştirilen 34 maddeli ve 8 boyuttan oluşan ölçek 5'li dereceleme ile kullanılmıştır.

Araştırmada kullanılan anket Nisan-Mayıs 2021 tarihinde Kapadokya Üniversitesinden uzak eğitim ile eğitim alıp mezun olan veya halen öğrenci olan ön lisans ve yüksek lisans öğrencilerine uygulanmıştır. Kapadokya Üniversitesinde halen aktif olarak Turist Rehberliği (Uzaktan) ön lisans programında 374 öğrenci ve Turist Rehberliği (Uzaktan - Tezsiz) Yüksek Lisans programında 100 öğrenci olmak üzere 474 öğrenci bulunmaktadır. Ayrıca bugüne kadar Turist Rehberliği (Uzaktan) ön lisans programından 418 öğrenci mezun olmuştur. Yüksek lisans programında ise henüz mezuniyet gerçekleşmemiştir. $\mathrm{Bu}$ sebeple çalışmanın evrenini 892 kişiden oluşmaktadır. Çalışmada örneklem alma yoluna gidilmemiştir. Çalışmada evrenin tamamına ulaşılmaya çalışılmıştır. Yaşanan pandemiden dolayı öğrencilere ve mezunlara anketler çevrimiçi olarak gönderilmiştir. Mezun ve öğrenciliği devam eden katılımcılara ikişer defa anket gönderilmesine, ilgili kurumdaki akademisyenlerle iletişime geçilmesine rağmen ulaşılabilen anket sayısı 148 olmuştur. DiLullo (1997), evreni temsil konusunda araştırmacıların verileri elde etme sürecinde zaman, maliyet ve ulaşma zorluklarından dolayı örneklem büyüklügü belirleyebileceklerini ifade etmektedir. Bu doğrultuda araştırma bu veriler ile gerçekleştirilmiş̧tir.

Ölçeğin güvenirliğinin belirlenmesi için Cronbach Alpha (CA) değeri hesaplanmıştır. CA değerlerinin 0.60'tan fazla bir değere sahip olması ölçeğin güvenilir olduğunu göstermektedir (Kalayc1, 2014). Faktör analizinde ise varyans oranlarının $\% 40$ ile $\% 60$ arasında bir orana sahip olması kabul edilebilirdir (Tavşancıl, 2010). Ölçek toplam 34 ifadeden oluşmakta ve CA değeri 0,96 olarak hesaplanmıştır. Ölçeğin KMO değeri 0,935 olarak hesaplanmıştır. Bu oran ölçeğin faktör analizine uygun yeterlilikte örneklem büyüklüğüne sahip olduğunu göstermektedir. Ölçeğin $p$ değeri $p<0,000$, Ki-kare değeri 4574,753 ve serbestlik derecesi değeri (sd) 561 olarak hesaplanmıştır. Bu oranlar verilerin çok değişkenli ve normal dağılıma sahip olduğunu kanıtlamaktadır (Altunışık, Coşkun, Bayraktaroğlu ve Yıldırım, 2010; Kalaycı, 2014). Gerçekleştirilen faktör analizi sonucu toplam 8 boyut elde edilmiştir.

Boyutlar ile ilgili CA değerleri hesaplanmıştır. Bu boyutlar ile ilgili istatistiki bilgiler ve CA değerleri Tablo 1'de verilmiştir. Elde edilen sonuçlar boyutların güvenilir olduğunu desteklemektedir (Kalaycı, 2014; Tavşanc1l, 2010). 


\begin{tabular}{cccc}
\multicolumn{5}{c}{ Tablo 1: Ölçek boyutları ile ilgili istatistikler } \\
\hline Boyut & İfade \# & CA & Toplam Varyans Açıklama \% \\
\hline Kişisel Uygunluk & 9 & 0,92 & 61 \\
Etkililik & 5 & 0,86 & 65 \\
Öğrenme & 5 & 0,87 & 69 \\
Program Değerlendirmesi & 4 & 0,91 & 69 \\
Teknoloji & 3 & 0,81 & 73 \\
Materyal & 3 & 0,92 & 87 \\
Değerlendirme & 3 & 0,69 & 83 \\
Destek Hizmetleri & 2 & 0,92 & 86 \\
\hline
\end{tabular}

\section{Bulgular}

Katılımcıların \%73'ü erkek ve \%27'si kadındır. Yaş aralığı kapsamında katılımcıların \%17,6'sı "30 ve altı" yaş grubunda, \%25,7'si " $31-35$ " yaş grubunda, \%21,6's1 " $36-40$ ” yaş grubunda, $\% 15,5$ ' $\mathrm{i}$ " $41-45$ " yaş grubunda ve \%19,6's1 "46 ve üzeri” yaş grubunda yer almaktadır. Eğitim düzeyi olarak katılımcıların \%66,9'u ön lisans ve \%33,1'i yüksek lisans düzeyindedir. Katılımcıların \%81,8'i öğrenciyken, \%18,2'si mezundur. Katılımcıların \%52,7'si ileri, \%44,6's1 orta ve \%2,7'si temel düzeyde bilgisayar kullanmaktadır. Katılımcıların ifadelere olan algıları ile ilgili ortalama değerleri Tablo 2'de özetlenmiştir.

Tablo 2 boyutlar kapsamında şu şekilde özetlenebilir;

- Kişisel uygunluk boyutunda katılımcıların katılmış oldukları en fazla olduğu ifade "uzaktan eğitim öğrenmenin kalıcı olmasını sağlamaktadır" iken, en az katıldıkları ifade "uzaktan eğitim sistemi öğretim uygulamaları bakımından öğrenciyi daha aktif hale getirmektedir" ifadesidir.

- Etkililik boyutunda katılımcıların en fazla katıldıkları ifade "gerektiğinde derslerin öğretim üyeleriyle etkileşime geçebildim" iken, en az katıldıkları ifade ise "öğrenci işlerinden kayıt, öğrenci belgesi gibi konularda yeterli desteği aldım" ifadesidir.

- Öğrenme boyutunda katılımcıların katıldıklarını en fazla dile getirdikleri ifade "Uzaktan eğitim iş yoğunluğumdan dolayı benim için uygundur" iken, en az katıldıklarını dile getirdikleri ifade ise "uzaktan eğitim geleneksel eğitimden etkilidir" ifadesidir.

- Programın değerlendirilmesi boyutunda katılımcıların algısının en fazla olduğu ifade "bu programın mesleki açıdan iyi olduğunu düşünüyorum" iken, en az algıya sahip olan ifade "program iyi bir şekilde tasarlanmıştı" ifadesidir.

- Teknoloji değerlendirilmesi boyutunda katılımcıların en fazla katıldıklarını dile getirdikleri ifade "uzaktan eğitim sisteminde ders öğretmeni ile dostça ve sosyal bir etkileşim içerisindeyim" iken, en az katıldıklarını dile getirdikleri ifade "uzaktan eğitim sisteminde öğretmenimle iletişimimde kendim gibi olabilmekteyim ve gerçekte nasıl bir öğrenci olduğumu göstermekteyim" ifadeleridir.

- Materyal boyutunda katılımcıların en fazla onaylamış olduğu ifade "ders kaynaklarındaki konular birbirleriyle tutarlıdı" iken, en az onayladıkları ifade ise "ders kaynaklarında öğrencilere kazandırılacak bilgi, davranış ve becerileri içeren amaçlar belirtilmiştir." ifadesidir.

- Değerlendirme boyutunda katılımcıların katılımlarının en fazla olduğu ifade "sistem üzerinden ders içeriklerine rahatlıkla erişebildim" iken, en az olan ise "öğrenme isteğimi azaltacak problemler yaşamadım" ifadesidir.

- Destek hizmetleri boyutunda katılımcıların algısının en fazla olduğu ifade "sınavdaki sorular ders içerikleriyle tutarlıydı" iken, en az algıya sahip olan ifade "final sınavları bilgi seviyemi değerlendirecek nitelikteydi" ifadesidir. 
Tablo 2: Katılımc1ların ifadelere olan algıları (boyutlar kapsamında)

\begin{tabular}{|c|c|c|}
\hline Boyut / İfade & $\overline{\mathbf{x}}$ & S.S. \\
\hline \multicolumn{3}{|l|}{ Kişisel Uygunluk } \\
\hline Uzaktan eğitim öğrenmenin kalıcı olmasını sağlamaktadır. & 4,41 & 0,932 \\
\hline Uzaktan eğitim öğrenciler için iyi bir öğrenme firsatı sunmaktadır. & 4,06 & 0,942 \\
\hline Uzaktan eğitimde verilen dersi anladım ve öğrendim. & 4,05 & 0,883 \\
\hline Uzaktan eğitim öğrencinin kendi hızında öğrenmesini sağlar. & 3,91 & 0,982 \\
\hline Program önlisans-lisansüstü eğitime hazırlayacak nitelikteydi. & 3,89 & 0,917 \\
\hline Uzaktan eğitim sistemini dersleri öğrenme için yeterlidir. & 3,69 & 1,035 \\
\hline Uzaktan eğitim sistemi zaman tasarrufu ve yer esnekliği sağlamaktadır. & 3,61 & 1,053 \\
\hline Ders materyalleri tek başıma öğrenmemi destekleyiciydi. & 3,51 & 1,078 \\
\hline $\begin{array}{l}\text { Uzaktan eğitim sistemi öğretim uygulamaları bakımından öğrenciyi daha aktif hale } \\
\text { getirmektedir. }\end{array}$ & 3,24 & 1,073 \\
\hline \multicolumn{3}{|l|}{ Etkililik } \\
\hline Gerektiğinde derslerin öğretim üyeleriyle etkileşime geçebildim. & 4,19 & 0,950 \\
\hline Derslerle ilgili problem yaşadığımda gerekli desteği alabildim. & 3,89 & 0,884 \\
\hline Derslerle ilgili talep ve önerilerimi iletebildim. & 3,81 & 0,985 \\
\hline Sisteme erişimde problem yaşadığımda teknik destek alabildim. & 3,78 & 0,972 \\
\hline Öğrenci işlerinden kayıt, öğrenci belgesi gibi konularda yeterli desteği aldım. & 3,48 & 1,175 \\
\hline \multicolumn{3}{|l|}{ Öğrenme } \\
\hline Uzaktan eğitim iş yoğunluğumdan dolayı benim için uygundur. & 4,51 & 0,861 \\
\hline Uzaktan eğitim evden eğitim alabilme rahatlığı sağlıyor. & 4,42 & 0,849 \\
\hline Uzaktan eğitim sistemi ihtiyaç duyduğum eğitimler açısından uygun bir alternatiftir. & 4,24 & 1,027 \\
\hline Uzaktan eğitimin bana uygun olduğunu düşünüyorum. & 4,16 & 1,082 \\
\hline Uzaktan eğitim geleneksel eğitimden etkilidir. & 2,93 & 1,187 \\
\hline \multicolumn{3}{|l|}{ Programın Değerlendirilmesi } \\
\hline Bu programın mesleki açıdan iyi olduğunu düşünüyorum. & 4,19 & 1,018 \\
\hline Dersler programın amacına uygundu. & 4,07 & 0,901 \\
\hline Ders içerikleri programın amacına uygundu. & 3,95 & 0,957 \\
\hline Program iyi bir şekilde tasarlanmıştı. & 3,91 & 0,935 \\
\hline \multicolumn{3}{|l|}{ Teknoloji } \\
\hline Uzaktan eğitim sisteminde ders öğretmeni ile dostça ve sosyal bir etkileşim içerisindeyim. & 4,03 & 0,971 \\
\hline Uzaktan eğitim sisteminde diğer öğrenciler ile dostça ve sosyal bir etkileşim içerisindeyim. & 3,89 & 0,993 \\
\hline $\begin{array}{l}\text { Uzaktan eğitim sisteminde öğretmenimle iletişimimde kendim gibi olabilmekteyim ve gerçekte } \\
\text { nasıl bir öğrenci olduğumu göstermekteyim. }\end{array}$ & 3,55 & 1,045 \\
\hline \multicolumn{3}{|l|}{ Materyal } \\
\hline Ders kaynaklarındaki konular birbirleriyle tutarlıydı. & 3,99 & 0,895 \\
\hline Ders kaynakları güncel bilgileri kapsamaktayd1. & 3,98 & 0,958 \\
\hline $\begin{array}{l}\text { Ders kaynaklarında öğrencilere kazandırılacak bilgi, davranış ve becerileri içeren amaçlar } \\
\text { belirtilmiştir. }\end{array}$ & 3,78 & 0,939 \\
\hline \multicolumn{3}{|l|}{ Değerlendirme } \\
\hline Sistem üzerinden ders içeriklerine rahatlıkla erişebildim. & 4,22 & 0,789 \\
\hline Sisteme erişimde problemler yaşamadım. & 3,74 & 1,084 \\
\hline Öğrenme isteğimi azaltacak problemler yaşamadım. & 3,64 & 1,178 \\
\hline \multicolumn{3}{|l|}{ Destek Hizmetleri } \\
\hline Sınavdaki sorular ders içerikleriyle tutarlıydı. & 4,10 & 0,898 \\
\hline Final sınavları bilgi seviyemi değerlendirecek nitelikteydi. & 3,87 & 1,069 \\
\hline
\end{tabular}

Katılımcıların demografik özellikleri ile boyutlara olan algı farklarını belirlemek amacıyla t-testi ve ANOVA analizleri gerçekleştirilmiştir. Cinsiyet ve eğitim düzeyi ile boyutlar arasında gerçekleştirilen t-test analizi sonuçlarına göre algı farkı olmadığı belirlenmiştir. Bilgisayar kullanma düzeyi ile boyutlar arasında gerçekleştirilen ANOVA analizine göre alg1 fark1 olmadığ ortaya çıkarılmıştır. Eğitim durumuna göre boyutlar arasında algı farkını belirlemek için gerçekleştirilen t-test analiz bulguları Tablo 3 'te özetlenmiştir. 


\begin{tabular}{|c|c|c|c|c|c|}
\hline Boyut & Eğt. Dur. & $\overline{\mathbf{x}}$ & $\mathbf{F}$ & Anlamlılık & t-değeri \\
\hline \multirow{2}{*}{ Kişisel Uygunluk } & Mezun & 299 & \multirow{2}{*}{,494 } & \multirow{2}{*}{, 086} & \multirow{2}{*}{1,729} \\
\hline & Öğrenci &,- 067 & & & \\
\hline \multirow{2}{*}{ Etkililik } & Mezun & 481 & \multirow{2}{*}{, 246} & \multirow{2}{*}{, $005 *$} & \multirow{2}{*}{2,827} \\
\hline & Öğrenci &,- 107 & & & \\
\hline \multirow{2}{*}{ Öğrenme } & Mezun &, 266 & \multirow{2}{*}{, 095} & \multirow{2}{*}{, 127} & \multirow{2}{*}{1,535} \\
\hline & Öğrenci &,- 059 & & & \\
\hline \multirow{2}{*}{ Program Değerlendirilmesi } & Mezun & ,362 & \multirow{2}{*}{, 102} & \multirow{2}{*}{, $037 *$} & \multirow{2}{*}{2,103} \\
\hline & Öğrenci &,- 081 & & & \\
\hline \multirow{2}{*}{ Teknoloji } & Mezun & 401 & \multirow{2}{*}{,453 } & \multirow{2}{*}{, $021^{*}$} & \multirow{2}{*}{2,338} \\
\hline & Öğrenci &,- 089 & & & \\
\hline \multirow{2}{*}{ Materyal } & Mezun & 426 & \multirow{2}{*}{, 102 } & \multirow{2}{*}{, $014 *$} & \multirow{2}{*}{2,491} \\
\hline & Öğrenci &,- 095 & & & \\
\hline \multirow{2}{*}{ Değerlendirme } & Mezun & 487 & \multirow{2}{*}{,035 } & \multirow{2}{*}{, $005 *$} & \multirow{2}{*}{2,870} \\
\hline & Öğrenci &,- 109 & & & \\
\hline \multirow{2}{*}{ Destek Hizmetleri } & Mezun &, 427 & \multirow{2}{*}{, 061} & \multirow{2}{*}{, $014 *$} & \multirow{2}{*}{2,496} \\
\hline & Öğrenci &,- 095 & & & \\
\hline
\end{tabular}

Tablo 3'te verildiği gibi eğitim durumuna göre etkililik, program değerlendirmesi, teknoloji, materyal, değerlendirme ve destek hizmetleri boyutlarında algı farkı vardır. Bulgulara göre fark olan boyutlara mezunların algısı öğrencilerin algılarından daha fazladır.

\section{Sonuç ve öneriler}

Bu çalışmada Eygü ve Karaman (2013)'ın geliştirmiş olduğu ve ilahiyat öğrencilerine uyguladıkları memnuniyet ölçeği anketi çevrim içi olarak uygulanmış ve elde edilen cevaplar farklı istatistik teknikleri kullanılarak değerlendirilmiştir. Ölçek ifadelerinde herhangi bir modifikasyon yapılmamıştır, çünkü bu ölçek her alanda uzaktan eğitim alanlara uygulanabilecek ifadelere sahiptir. Ölçeğin güvenirlik ve geçerliliği için faktör analizi gerçekleştirilmiş ve boyutların CA değerleri hesaplanmıştır. Elde edilen sonuçlar ölçeğin güvenirlik ve geçerliliğini kanıtlamaktadır. Ayrıca boyutların toplam varyans açıklama oranlarına bakılınca ölçeğin turist rehberliği uzaktan eğitim programı için uygun olduğu görülmektedir.

Araştırma sonuçları değerlendirildiğinde, literatürde daha önce örgün eğitim alan öğrencilerin uzaktan verilen derslerin memnuniyetini ölçmeye yönelik yapılmış olan akademik çalışmaların aksine, uzaktan eğitimi gönüllü bir tercih olarak seçenlerin daha çok memnun oldukları görülmektedir. $\mathrm{Bu}$ memnuniyetin özellikle örgün eğitime fırsat bulamayan, zamanı sınırlı ve mekansal olarak bu eğitimin verildiği mekâna gidemeyenlerin ihtiyaç duydukları eğitim ihtiyacının karşılanması sebebiyle olduğu düşünülmektedir. Ayrıca araştırmaya katılan katılımcıların ortalama yaş durumuna bakıldığında sadece $\% 17,6$ sının otuz yaş ve altını oluşturduğu, \%21,6'sının ise 46 yaş ve üzeri katılımcıların oluşturduğu görülmektedir. Bu da bu turist rehberliği uzaktan eğitim programına katılan kişilerin klasik öğrencilik dönemlerini geçirmiş, yaşamsal sorumlulukları yüksek, çalışma hayatında aktif olarak görev alan mesai saatleri dışında verilen bu eğitimleri kendileri için firsata dönüştürmüş kişiler olduklarını düşündürmektedir. Ayrıca katılımcıların yaş durumunun klasik öğrenci profilinden bir hayli yüksek olmasına rağmen, sadece \%2,7'sinin temel düzeyde bilgisayar kullanıcısı olduğu, kalan kişilerin ise orta ve üst düzey bilgisayar kullanıcıları oldukları görülmektedir. Bu da bu tür programları tercih edilmesinin bilgisayar kullanıcı bilgi düzeyleri ile doğru orantılı olduğunu ortaya koymaktadır. Araştırmaya katılanların \%27'sinin kadın olması, mevcut TUREB'in (Turist Rehberleri Birliği) sitesinde kayıtlı 11.376 rehberin \%33 ile 3.765'inin kadın olması ile de uyumludur (tureb.org, 08.06.2021).

Turist rehberliği uzaktan verilen eğitimin etkililiği ile ilgili olarak, öğrencilerin öğretim elemanları ile gerek görmesi halinde etkileşime geçme konusunu olumlu değerlendirirken benzer etkileşimin öğrenci işlerinde sağlanamadığı görülmektedir. Bu da turist rehberliği uzaktan öğrenim gören kişilerin öğrenci işlerine erişimin örgün öğrencilerin aksine sadece mail, whatsapp ve telefon ile ulaşım imkanının olması kaynaklı olduğu düşünülmektedir. Bu konuda üniversitede bulunan toplam kalite yönetimi anlayış1 çerçevesinde uzaktan erişim yoluyla yapılan başvurulara geri dönüş için 24 saat ile 48 saat gibi 
maksimum bir sürenin belirlenerek bu hedefin gerçekleştirilmesi bu algının düzeltilmesine yardımcı olabilir.

Katılımc1lar öğrenme boyutunda mevcut öğrenme modelinin (turist rehberliği uzaktan eğitimin) iş yoğunlukları sebebiyle kendileri için en uygun program olduğunu ifade ederken, verilen turist rehberliği uzaktan eğitimin geleneksel eğitimin yerini tutmayacağını belirtmektedir. Bu da zamansal ve mekansal sorunları olan kesimlerin eksik ve ihtiyaç duydukları eğitimin tamamlanması için uzaktan öğretimin çok önemli bir firsat olmasıyla beraber hiçbir zaman geleneksel eğitimin \%100 alternatifi olmayacağını ortaya koymaktadır. Dolayısıyla zamanında bu ve benzeri eğitimleri alma imkânı bulamamış kişilerin ihtiyaç duydukları bu eğitimi alabilmeleri açısından ve T.C. Anayasası'nın 42. maddesine göre "kimse, eğitim ve öğrenim hakkından yoksun bırakılamaz" ilkesi gereğince arttırılması önerilmektedir. Turist rehberliği programında verilen dersler nitelikleri itibariyle uzaktan eğitime uygun derslerdir. Turist rehberliği uzaktan eğitimden mezun olan herkesin turist rehberi çalışma kartı alması beklenmemektedir. Ancak çalışma kartı almak isteyenler TUREB tarafindan uygulama gezilerine katılmak ve uygulama gezisi sonrası gerçekleştirilen sınavda başarılı olmak zorundadır. Dolayısıyla turist rehberliği uzaktan programda öğrencilerin elde ettikleri çıktıları uygulama gezilerinde pekiştirerek pratiğe dökmektedir.

Programın genel değerlendirilmesinde ders programlarının ve içeriklerinin amaca uygunluğu ve materyal boyutunda ise mevcut ders konularının tutarlılı̆̆ 1 yüksek bulunurken, ders sonucunda öğrenciye kazandırılacak bilgi, beceri ve davranış konusunda tutarlılık düşük bulunmuştur. Bu yönüyle Kapadokya Üniversitesinin sahip olduğu SOBE (Son Bilgiyi Önceleyen Eğitim - Öğretim) (kapadokya.edu.tr, 08.06.2021) sisteminin öğrenciye yeteri kadar aktarılmadığ 1 şeklinde değerlendirilebilir. SOBE eğitim felsefesinin daha iyi anlaşılması ve öğrencilere aktarılabilmesi için öğretim elemanlarına eğitim verilmesi yararlı olabilir. Diğer taraftan literatüre bakıldığında Eygü ve Karaman (2013) tarafından gerçekleştirilen çalışmanın da araştırmanın sonuçlarını destekler nitelikte olduğu görülmektedir.

Yaşanılan COVID-19 süreci sebebiyle günlük hayatın bir parçası haline gelen "Uzaktan Eğitim" kavramı yaşanan bu süreç sebebiyle pandemi sona erse bile etkilerinin uzun süre devam edeceği düşünülmektedir. Yaşanan bu sürecin zorunluluğu sebebiyle uzaktan eğitime mesafeli ve önyargıll olan kesimlerin bunu bizzat deneyimlemiş olmaları sebebiyle olumlu sonuçları olacağı değerlendirilmektedir. Bundan sonra oluşturulacak eğitim programlarında etkililiği kanıtlanmış ve olmazsa olmaz olan geleneksel eğitim programlarının yanında bu eğitimden herhangi bir sebeple faydalanamamış olanlar için de bu tür uzaktan eğitim programlarının özellikle sosyal bilimler alanında daha da yaygınlaştırılması önerilmektedir.

İyi kurgulanmış ve öğrencilerin beklenti ve ihtiyaçları iyi tespit edilmiş bu tür programların etkinliklerinin de yüksek olacağı düşünülmektedir. Uzaktan eğitim programların oluşturulmasında geleneksel programların açılmasından farklı olarak, bu eğitimden faydalanacak potansiyel ve hedef kişilerinin iyi tespit edilerek onların yaş, cinsiyet ve öğrenim durumlarına uygun programlar geliştirilmelidir. Yüz yüze verilen eğitimlerde eğitici ve eğitimi alanlar interaktif bir şekilde iç içe olup, eğitici sınıfın ilgi ve anlama düzeyini kuracağı göz temasıyla sağlayabilmektedir. Uzaktan eğitimde oluşan bu açığı gidermek için oluşturulan ders programlarında öğrencinin dikkatini diri tutacak onu ekran başından ayrılmasına engel olacak şekilde tasarlanmalıdır. Bu konuda profesyonelce geliştirilmiş "Kahoot" örneğinde olduğu gibi birçok yazılım ve uygulamadan faydalanmak ile birlikte hazırlanacak olan ders sunumlarının daha fazla görsel - işitsel öğeler içermesi tavsiye olunur. 
Kaynakça

Adnan, M. ve Anwar, K. (2020). Online learning amid the covid-19 pandemic students perspectives. Journal of Pedagogical Research, 2, 45-51.

Afşar, B. ve Büyükdoğan, B. (2020). Covid-19 Pandemisi Döneminde İ̈BF ve SBBF öğrencilerinin uzaktan eğitim hakkındaki değerlendirmeleri. Karatay Sosyal Araştırmalar Dergisi, 5, 161-182.

Akdu, U., Karakaş, D., Zurnacı, J. ve Tabu Ö. (2018). Turizm rehberliğinde alan uzmanlığı önerisi: Sağlık turizmi rehberliği. Turist Rehberliği Dergisi, 1(2), 124-138.

Akyürek, M. (2020). Uzaktan eğitim: Bir alanyazın taraması. Medeniyet Eğitim Araştırmaları Dergisi, $4(1), 1-9$.

Altunışı, R., Coşkun, R., Bayraktaroğlu, S. ve Yıldırım, E. (2010). Sosyal bilimlerde araştırma yöntemleri: SPSS uygulamalı. Sakarya Yayıncılık.

Bahar, M. (2020). Turist rehberliğinde uzmanlaşma: gastronomi rehberliği açısından ön lisans ve lisans programlarının değerlendirilmesi. S. Bornovalı (Ed.). III. Ulusal Turist Rehberliği Kongresi, (262-270). Tureb.

Bayram, M. (2020). Uzaktan iş sağlığı ve güvenliği eğitim kalitesinin katılımcıların memnuniyet algıları üzerinde etkisi. The Journal of Social Science, 4(7), 110-120.

Betts, K. (2014). Factors influencing faculty participation \& retention in online \& blended education. Online Journal of Distance Learning Administration, 17(1), 1-17.

Biner, P., Dean, R. S. ve Mellinger, A. E. (1994). Factors underlying distance learner satisfaction with televised college-level courses. The American Journal of Distance Education, 1, 60-71.

Cansu, E. ve Bahar, M. (2021). A Comparative analysis between the numbers of tourist guides and the tourists visiting Turkey. Journal of Humanities and Tourism Research, 11(2), 420-432.

Chang, S. C. ve Tung, F. C. (2008). An empirical investigation of students' behavioural intentions to use the online learning course websites. British Journal of Educational Technology, 39(1), 71-83.

Çakmak, T. F. ve İstanbullu Dinçer, F. (2018). Turist rehberliği bölümleri ders programlarının "Türk kimliği” açısından incelenmesi. International Journal of Contemporary Tourism Research, 2(2), 67-75.

Dilullo, L. K. (1997). A Post hoc power analysis of inferential research examining the relationship between mathematic anxiety and mathematic Performance. [Doktora Tezi], Auburn University.

Duman, G. ve Mil, Z. (2008). Akademik görüş: "turist rehberliği ve eğitimi". Seyahat ve Otel İsletmeciliği Dergisi, 5(4), 107-122.

Eğitim yöntemimiz (t.y.) 08 Haziran 2021 tarihinde https://www.kapadokya.edu.tr/hakkimizda/egitimyontemimiz adresinden erişildi.

Eker, N. ve Zengin, B. (2016), Turist rehberliği eğitiminin değerlendirilmesi: profesyonel turist rehberleri üzerinde bir uygulama. Ë̆itim ve Öğretim Araştırmaları Dergisi, 5(4), 65-74.

Eygü, H. ve Karaman, S. (2013). Uzaktan eğitim öğrencilerinin memnuniyet algıları üzerine bir araştırma. Kırıkkale Üniversitesi Sosyal Bilimler Dergisi, 3(1), 36-59.

Gökbulut, B. (2021). Uzaktan eğitim öğrencilerinin bakış açısıyla uzaktan eğitim ve mobil öğrenme. Ĕ̈itim Teknolojisi Kuram ve Uygulama, 11(1), 160-177.

Gökçe, A. (2008). Küreselleşme sürecinde uzaktan eğitim. Dicle Üniversitesi Ziya Gökalp Eğitim Fakültesi Dergisi, 11, 1-12.

Gökmen, Ö., Duman, İ. ve Horzum, M. (2016). Uzaktan eğitimde kuramlar, değişimler ve yeni yönelimler. Açıkögretim Uygulamaları ve Araştırmaları Dergisi, 2(3), 29-51.

Gunawardane, C. N. ve McIsaac, M. S. (2004). Distance education. D. H. Jonassen (Ed), Handbook of Research on Educational Communications and Technology içinde (ss. 355-395) Lawrence Erlbaum Associates,

Güven, Ö. Z. ve Ceylan, U. (2014), Lisans ve ön lisans düzeyinde turizm rehberliği eğitimi veren okullardaki müfredatların turizm rehberliği meslek yönetmeliğine uygunluğunun incelenmesi. A. Kilıçlar (Ed.). 15. Ulusal Turizm Kongresi (186-195). Detay.

Holmberg, B. (1989). Theory and practice of distance education. Routledge.

Ilgaz, H. ve Aşkar, P., (2009). Çevrimiçi uzaktan eğitim ortamında topluluk hissi ölçeği geliştirme çalışması. Turkish Journal of Computer and Mathematics Educition, 1(1), 27-35.

Işık, A., Işık, İ. ve Güler, İ. (2008). Uzaktan eğitimde güvenlik uygulamaları. Bilişim Teknolojileri Dergisi, 1(2), 1-3. 
Kaçan, A. ve Gelen, İ. (2020). Türkiye'deki Uzaktan Eğitim Programlarına Bir Bakış. Uluslararası Eğitim Bilim ve Teknoloji Dergisi, 6(1), 1-21.

Kalaycı, Ş. (2014). SPSS uygulamalı çok değişkenli istatistiksel teknikler. Asil Yayıncılık.

McGivney, V. (2004). Understanding persistence in adult learning. Open Learning: The Journal of Open, Distance and e-Learning, 19(1), 33-46.

Merisotis, J. P. ve Phipps, R. A. (1999). What's the difference? outcomes of distance vs. traditional classroom-based learning. Change, 31(3), 12-17.

Metin, A., Karaman, A. ve Şaştım, Y. (2017). Öğrencilerin uzaktan eğitim sistemine bakış açısı ve uzaktan eğitim İngilizce dersinin verimliliğinin değerlendirilmesi: Banaz meslek yüksekokulu. Karabük Üniversitesi Sosyal Bilimler Enstitüsü Dergisi, 7(2), 640-652.

Mokoena, S. (2017). Student teachers' experiences of teaching practice at open and distance learning institution in South Africa. Turkish Online Journal of Distance Education, 18(2), 122-133.

Nasser, R. ve Abouchedid, K. (2010). Attitudes and concerns towards distance education:The case of Lebanon. Online Journal of Distance Learning Administration, 3(4), 1-12.

Özkılıçcı, G. ve Cantürk, U. P. (2020). Bilişsel esneklik ile uzaktan eğitim memnuniyetinin ilişkisi: negatif duygulanımın aracı rolü. İstanbul Ticaret Üniversitesi Sosyal Bilimler Dergisi, 19(39), 1167-1181.

Poellhuber, B., Anderson, T. ve Roy, N. (2011). Distance students' readiness for social media and collaboration. The International Review of Research in Open and Distributed Learning, 12, $102-$ 125.

Sadera, W., Robertson, J., Song, L. ve Midon, M. (2009). The role of community in online learning success. MERLOT Journal of Online Learning and Teaching, 5(2), 277-284.

Sujarwo, S., Sukmawati, S., Akhiruddin, A., Ridwan, R. ve Siradjuddin, S.S. (2020). An analysis of university students' perspective on online learning in the midst of covid-19 pandemic. Jurnal Pendidikan dan Pengajaran, 53(2), 125-137.

Tavşancıl, E. (2010). Tutumların ölçülmesi ve SPSS ile veri analizi. Nobel.

Teacher task force calls to support 63 million teachers touched by the covid-19 crisis. 27 Mart 2020 tarihinde https://en.unesco.org/news/teacher-task-force-calls-support-63-million-teacherstouched-covid-19-crisis adresinden erişildi.

Temizkan, S. P. ve Ergün, B. (2018). Türkiye'de turist rehberliği öğretiminin değerlendirilmesi. Turist Rehberliği Dergisi (TURED), 1(2), 95-104.

Topsakal, Y. (2021). Lisansüstü düzeyde turist/turizm rehberliği eğitimi veren programların müfredatlarının incelenmesi ve öneriler. Ankara Hacı Bayram Veli Üniversitesi Turizm Fakültesi Dergisi, 24(1), 99-115.

Tuncer, M. (2007). Uzaktan eğitim ve uzaktan eğitim teknolojisinin öğrenen sağlı̆̆ına etkileri. Firat Üniversitesi Doğu Araştırmaları Dergisi, 5(3), 26-31.

TUREB (t.y.). 08 Haziran 2021 tarihinde www.tureb.org adresinden erişildi.

Yağc1, K., Efendi, M. ve Akçay S. (2019). Turist rehberliği öğrencilerinin uzaktan eğitim kavramına bakış açıları. Journal of Travel and Tourism Research, 14, 118-136.

Yenipınar, U. ve Kardaş, K. (2019), Turizm rehberliği bölümleri müfredat geliştirme önerisi. Journal of Travel and Tourism Research, 15, 1-26.

\section{Etik kurul onayı}

Kapadokya Üniversitesi Etik Kuruluna 20.04.2021 tarih ve 29533901-204.01.07-12465 say1s1 ile başvurulurmuş ve 27.05.2021 tarih ve 2021.05 karar no ile çalışmanın yapılması onaylanmıştır.

\section{Araştırmacıların katkı oranı beyanı}

$\mathrm{Bu}$ çalışmada tüm yazarların makale sürecine vermiş oldukları katkı eş ve eşit düzeydedir.

Çıkar çatışması beyanı

Yapılan bu araştırma herhangi bir kurum, kişi veya kuruluş ile herhangi bir çıkar çatışmasına sebep olmamaktadir. 